\title{
The clinical use of regenerative therapy in COPD
}

This article was published in the following Dove Press journal:

International Journal of COPD

12 December 2014

Number of times this article has been viewed

\section{Roberto Lipsi' \\ Paola Rogliani' \\ Luigino Calzetta ${ }^{2}$ \\ Andrea Segreti' \\ Mario Cazzola'}

'Department of Systems Medicine, University of Rome Tor Vergata, Rome, Italy; ${ }^{2}$ Department of Pulmonary Rehabilitation, San Raffaele Pisana Hospital, Istituti di Ricovero e Cura a Carattere Scientifico, Rome, Italy

Correspondence: Mario Cazzola Unità di Farmacologia Clinica Respiratoria, Dipartimento di Medicina dei Sistemi, Università di Roma Tor Vergata, Via Montpellier I, Rome 00I33, Italy

Emailmario.cazzola@uniroma2.it
Abstract: Regenerative or stem cell therapy is an emerging field of treatment based on stimulation of endogenous resident stem cells or administration of exogenous stem cells to treat diseases or injury and to replace malfunctioning or damaged tissues. Current evidence suggests that in the lung, these cells may participate in tissue homeostasis and regeneration after injury. Animal and human studies have demonstrated that tissue-specific stem cells and bone marrowderived cells contribute to lung tissue regeneration and protection, and thus administration of exogenous stem/progenitor cells or humoral factors responsible for the activation of endogenous stem/progenitor cells may be a potent next-generation therapy for chronic obstructive pulmonary disease. The use of bone marrow-derived stem cells could allow repairing and regenerate the damaged tissue present in chronic obstructive pulmonary disease by means of their engraftment into the lung. Another approach could be the stimulation of resident stem cells by means of humoral factors or photobiostimulation.

Keywords: chronic obstructive pulmonary disease, stem cells, regenerative therapy, all-trans retinoic acid, photobiostimulation

\section{Introduction}

Many devastating and currently untreatable human diseases arise from the loss or malfunction of specific cell types in the body. This is particularly true for age-related diseases such as lung diseases, neurologic degenerative diseases, type 2 diabetes, and heart failure, ${ }^{1}$ as well as for other medical conditions such as trauma, infarction, and burns. ${ }^{2}$ Frequently, patients affected by these kind of diseases are limited to organ or tissue transplantation as their only treatment option, but there are only a few organ and tissue donors, and as a consequence the discrepancy between organ need and organ availability is huge. Furthermore, posttransplantation life is conditioned by a lifelong need for immunosuppressive therapy, a high rate of morbidity, a poor quality of life, and a variable prognosis. ${ }^{3}$

Regenerative therapy or stem cell therapy is an emerging field of treatment based on stimulation of endogenous resident stem cells or administration of exogenous stem cells to treat diseases or injury and to replace malfunctioning or damaged tissues. ${ }^{4}$ Classically, stem cells are functionally defined as cells showing indefinite self-renewal as well as a clonal, multipotent differentiation repertoire within a cellular hierarchy. ${ }^{5}$ Regenerative therapy is a promising and rapidly growing area of investigation involving ex vivo bioengineering of functional tissues that could be implanted into patients, and thus it can be considered an alternative to organ transplantation. 


\section{Global burden of COPD and limitations to current management strategies}

Chronic obstructive pulmonary disease (COPD) represents a common cause of morbidity and mortality worldwide, with an increasing and substantial economic and social burden. ${ }^{6}$ According to World Health Organization estimates, around 65 million people have moderate to severe COPD; more than 3 million people die of COPD each year, which corresponds to $5 \%$ of all deaths globally; and almost $90 \%$ of COPD deaths occur in low- and middle-income countries. ${ }^{7}$ It is the fifth leading cause of death. Total deaths from COPD are projected to increase by more than $30 \%$ in the next 10 years unless urgent action is taken to reduce the underlying risk factors, especially tobacco use. Estimates suggest COPD will become the third leading cause of death worldwide in $2030{ }^{8}$ The enormous burden of COPD requires effective treatment that is able to influence the natural history of the disease.

Chronic inflammation plays a central role in COPD. It is characterized by increased numbers of neutrophils, activated macrophages, and activated $\mathrm{T}$ lymphocytes (Tc1 and Th1 cells). Neutrophils, macrophages, and cytotoxic $\mathrm{T}$ lymphocytes release an array of proteolytic enzymes, including serine- (elastase, proteinase 3 ), cysteine(cathepsin S), and metalloproteases. These proteinases cleave components of the extracellular matrix, elastin fibers, and collagen, generating elastin fragments or collagen-derived peptides such as proline-glycine-proline, which have been shown to be chemotactic for monocytes, the precursor cell for macrophages or neutrophils. All this will result in the destruction of alveolar tissue (formation of emphysema), inhibition of normal repair and defense mechanisms (fibrosis formation in distal airways), and airflow obstruction expressed primarily by increased numbers of goblet cells, mucus gland hyperplasia, fibrosis, narrowing and reduction in the number of small airways, and airway collapse because of the destruction of the attachments of the alveolar wall resulting in emphysema. ${ }^{9}$

Another important aspect in the pathogenesis of COPD is the increased burden of oxidative stress resulting from smoke-related chronic inflammation. There are several evidences in literature that lung development and regeneration depend on the coordination of signals and molecular pathways involving retinoic acid, Notch, fibroblast growth factor, transforming growth factor $\beta$, and so on. It has been demonstrated that these pathways would be altered in a condition of chronic inflammation, such as COPD, precluding or at least reducing the lung's regenerative capacities. ${ }^{10}$

The management of COPD actually includes primary and secondary prevention, early detection, staging of severity, assessment of reversibility with bronchodilators and inhaled corticosteroids, chronic pharmacotherapy, pulmonary rehabilitation, and treatment of comorbidities. ${ }^{6}$ When respiratory failure is detected, long-term oxygen therapy must be prescribed, and in some cases (characterized by emphysema), lung surgery, including lung volume reduction, should be considered. ${ }^{6}$

The introduction and the association of new bronchodilators into the therapeutic choices of COPD have significantly improved the quality of life of patients. ${ }^{11}$ However, current therapeutic approaches for COPD do not allow us to reduce the decline of lung function and to interfere with the progressive and unfavorable course of the disease. ${ }^{6}$ Moreover, anti-inflammatory therapies currently available provide little or no benefit in patients with COPD and may have detrimental effects. ${ }^{9}$ Therefore, all available therapeutic options are actually considered symptomatic, and there is no effective treatment for the formation of emphysema caused by the destruction of alveolar tissue, which is one of the biggest challenges in the development of therapeutic agents for COPD.

In view of the current disappointing status of available pharmaceutical agents, there is an urgent need for alternative and more effective therapeutic approaches that not only will help relieve patient symptoms but will also affect the natural course of the disease.

\section{Outline of advances in lung regeneration therapy: from the classical model to the use of the stem cells}

Epimorphosis is the term used to define the complete replacement of a native structure and function at the anatomic site of excision by local cell proliferation and differentiation. An example of this process is the limbs or tails of the salamander, ${ }^{12,13}$ the antlers of deer, ${ }^{14}$ and the digit tips of rodents. ${ }^{15}$ In contrast, the lung as a whole organ in mammals does not regenerate in this orthotopic way (from the site of excision), but similar to liver and kidney, it develops a compensatory growth by hyperplasia or hypertrophy. ${ }^{15}$ In humans, lung regeneration such as spontaneous formation of new lung acini ("neo-alveolarization" or "realveolarization") after partial pneumonectomy (PPN) occurs in children younger than 3 years, but not in adulthood. ${ }^{16,17}$ 
A lot of animal species have been studied to develop a fundamental understanding of the cellular and the molecular basis of realveolarization, and the most important understanding has been derived from murine studies because of the availability of transgenic strains. ${ }^{18}$

\section{The PPN model}

This model has been proposed to study the potential mechanisms of tissue regeneration after lung damage. In fact, after PPN, a sudden decrease in the number of alveoli occurs, and for this reason, the organism develops an immediate and a long-term response to maintain the homeostasis. The early or immediate response arises from the reduction of the alveolar surface area, which reduces gas diffusion capacity and increases the transpulmonary pressure in the first 2 days after PPN because the residual lung receives the entire cardiac output. ${ }^{19,20}$

At least in rats, these effects cause an overexpression of genes as c-fos and JunB transcription factors, early growth response protein 1, fibroblast growth factor 2, and platelet-derived growth factor, resulting in a promotion of growth and survival of lung cells. ${ }^{16}$ Moreover, hypoxiainduced genes such as vascular endothelial growth factor, epidermal growth factor, and hepatocyte growth factor are overexpressed. ${ }^{16}$ Furthermore, mechanical stress plays an important role in compensatory growth because induced unilateral diaphragmatic paralysis leads to decreased cyclic respiratory stretch, resulting in a decreased compensatory growth response. ${ }^{21}$

From 3 to 14 days after PPN, progenitor cells from all areas of the distal lung participate in the realveolarization process, as evidenced by a heightened DNA synthesis documented by incorporation of tritiated thymidine ${ }^{22}$ or bromodeoxyuridine ${ }^{23,24}$ during the period of realveolarization. Finally, reconstruction of alveolar septae is mediated by the mesenchyme regulating the fate of early lung endodermal cell population. ${ }^{25,26}$

\section{Stem cells to generate new lungs}

Ex vivo bioengineering of functional lung tissue that could then be implanted into patients with diseases such as COPD is an emerging area of investigation. This approach has been successfully used in regeneration of other tissues including skin, vasculature, cartilage, bone, and trachea, and more recently, in more complex organs including lung, heart, and liver. ${ }^{27}$ This technique uses either biologically derived or fabricated 3-dimensional matrix scaffolds seeded with autologous progenitor cells obtained from the transplant recipient to produce functioning lung tissue. The use of autologous cells would eradicate the need for immunosuppressive drugs, but the current state of the art in manufacturing technologies is unable to recreate the complex 3-dimensional architecture of the lung, ${ }^{28}$ although tubes shaped like upper airways, such as trachea and bronchi, have already been engineered in vitro, coated with various cell preparations such as bone marrow (BM) derivatives, and surgically grafted into patients who have regions of tracheal or bronchial atresia. ${ }^{5}$

An alternative to avoid this limit consists of decellularization of the whole lungs, in which all cells and cellular materials are removed, leaving an intact 3-dimensional scaffold composed of innate extracellular matrix, preserving native airway and vascular structure and providing an acellular matrix for cell seeding and functional recellularization..$^{29,30}$ This technique was originally described by Lwebuga-Mukasa et al in $1986 .{ }^{30} \mathrm{~A}$ decellularized rat lung was used to study the effect of the basement membrane on the growth of type 2 alveolar epithelial cells. The technique was reinvigorated in 2010, and several laboratories are currently exploring this approach in murine experimental models. ${ }^{31-33}$ After culture within a bioreactor, the organs are reimplanted into syngeneic recipients and demonstrate efficient gas exchange. However, the lungs ultimately fail after several hours to days because of a combination of intravascular coagulation (likely resulting from incomplete endothelialization of the decellularized vasculature) and defects in barrier function, leading to exudation of fluid into the airways. This technique also provides a novel culture system to study cell-matrix interactions and environmental factors such as mechanical stretch on lung cell growth and development. However, one key challenge will be the delivery of mesenchymal populations to the interstitium, and particularly the delicate septa. ${ }^{34}$

\section{Clinical use of regenerative therapy in lung diseases}

Stem cells are considered to be capable of self-renewal and differentiation into several cellular subtypes, depending on their origin and the resident microenvironment. In humans, stem cells can be subdivided into two main categories: embryonic stem cells and adult stem cells. ${ }^{35}$ The latter are located in tissues such as blood, BM, adipose tissue, kidney, liver, heart, and the lungs and can be subdivided into multipotent (eg, mesenchymal stem cells [MSCs]) or unipotent (eg, epithelial and endothelial progenitor cells) types on the basis of their differentiation capacity, whereas embryonic 
stem cells that originate from embryonic blastocystis provide a source of cells throughout the life and act during wound healing. ${ }^{36}$ Current evidence suggests that in the lung, these cells may participate in tissue homeostasis and regeneration after injury $y^{4,37}$ and are located within the lung itself in distal airway niches, called resident progenitor cells (alveolar, endothelial, and interstitial), ${ }^{38}$ or in distant sites such as the blood, BM, adipose tissue, and other sites., ${ }^{43}$ The lung could respond to injury and stress by activating stem cell populations and/or by re-entering the cell cycle to repopulate lost cells. ${ }^{5}$

In patients with COPD, there is endothelial dysfunction and lower numbers of circulating endothelial progenitor cells. For this reason, endothelial progenitor cells are candidates for cell therapy and have the potential to repair damaged endothelia. ${ }^{40}$

Endothelial progenitor cells were initially evaluated in the treatment of pulmonary hypertension. ${ }^{41}$ Later, because of the great need to find effective therapies to treat patients affected by end-stage chronic lung diseases, there has been a growing number of studies on stem cells and cell therapies in lung biology and diseases. Despite these studies producing very interesting information, issues related to the unresolved ethical concerns on the use of this approach and, above all, to its security, as well as the partial understanding of the properties of adult stem cells, have limited the number of preclinical and clinical studies in emphysema. Because it is not difficult to instill exogenous cells into the lung through both the airway and circulation, it is expected that the efficacy of cell delivery is naturally high. Actually, this is very interesting because it seems to offer a real therapeutic approach to a disease that, lung transplantation apart, has no proven therapies to modify its course. ${ }^{39}$

Shigemura et al demonstrated that adipose-derived stem cells ameliorated pulmonary emphysema in an experimental model by secreting large amounts of hepatocyte growth factor. ${ }^{42,43}$ Other humoral factors such as epidermal growth factor and cytokine-induced neutrophil chemoattractant-1, were reported to increase by delivery of MSCs in COPD models and were involved in the repair of tissues in COPD. ${ }^{44,45}$ Similar protective paracrine effects of BM-derived MSCs have also been demonstrated by several investigators in experimental models of pulmonary emphysema induced by the irradiation and instillation of papain ${ }^{46,47}$ or by the intratracheal administration of elastase. ${ }^{44}$ Furthermore, in a murine model of emphysema, it was shown that the systemic injections of both murine and human adipose-derived stem cells significantly improved the pulmonary and systemic injury induced by cigarette smoke by attenuating the cigarette smoke-induced increase in the number of macrophages and polymorphonuclear leukocytes in bronchoalveolar lavage fluid and were demonstrated to exert a lung vascular protective function by releasing paracrine factors. ${ }^{48}$

In healthy people, basal, secretory, or club cells (formerly known as Clara cells) and type 2 alveolar epithelial cells, which are epithelial progenitor cells with large regenerative and differentiative capacity situated in small protected niches across the tracheobronchial tree, as well as most types of lung epithelial cells, with the exception of airway ciliated cells, can proliferate and expand after injury to promote repair and move to the sites of injury during the wound. ${ }^{5}$ To the contrary, in genetically predisposed individuals or in patients with chronic lung disease, these cells lose in part or completely their regenerative and differentiative capacity and cause abnormal healing tissue repair and restoration. In addition, a limited reservoir of resident stem cells causes the same effect. ${ }^{10}$ Therefore, it seems likely that alveologenesis might also be induced by the reactivation of developmental pathways that are in an inactive state. ${ }^{49}$ In any case, it is fundamental to always consider that there is little evidence suggesting endogenous MSCs are recruited from the BM to lung tissue, ${ }^{50}$ as a consequence, the injection of these cells into lung tissue should be viewed as an artificial, engineered therapy, rather than an augmentation of naturally occurring mechanisms for lung repair. ${ }^{5}$

The all-trans retinoic acid (ATRA) derived from vitamin A (retinol), which acts via nuclear retinoic acid receptors and modulates the synthesis of elastin, an essential structural component of the lung matrix in neonatal fibroblasts, is the major candidate in alveologenesis. Interestingly, there is documentation of a distorted alveolar formation in mice mutant for retinoic acid receptor genes. ${ }^{51}$ Experimental studies have documented that at least in rats, exogenous instillation of ATRA is able to induce alveolarization, ${ }^{52}$ but clinical assessment of oral administration of ATRA yielded discouraging results when related to the radiological and functional parameters, although it documented the safety of this therapeutic approach. ${ }^{53,54}$ Two trials, the REPAIR (Retinoid Treatment of Emphysema in Patients on the $\alpha_{1}$-Antitrypsin International Registry $)^{55}$ and the TESRA (Treatment of Emphysema With a Gamma-Selective Retinoid Agonist), ${ }^{56}$ have evaluated the efficacy and safety of palovarotene, an oral $\gamma$-selective retinoid agonist, in patients with $\alpha_{1}$-antitrypsin deficiency. Apparently, palovarotene is useful only in COPD patients with smoke-induced emphysema, 
and mainly in those patients with lower lobe emphysema. ${ }^{56}$ Several groups are investigating the therapeutic potential of MSC therapy in COPD patients, but trials are still ongoing. ${ }^{57}$ Very recently, it has been shown that integrin $\alpha 1$ and $\beta 3$ are factors responsible for the differentiation-inducing effect on human alveolar epithelial stem cells by ATRA, and the pulmonary administration of integrin nanoparticles regenerated collapsed alveoli. ${ }^{58}$ These findings suggest that integrin nanoparticles might be effective as novel COPD treatment target compounds.

\section{Potentials of mesenchymal stem cells and low level laser}

Cell therapy with stem cells represents a potential novel therapeutic approach to degenerative diseases. There are reports in the literature showing pulmonary regeneration after the use of BM cells in animal models of pulmonary emphysema. ${ }^{49}$ In fact, BM cells infused in the blood stream can be recovered or detected in pulmonary tissue. ${ }^{59,60}$

Many aspects of the pathogenesis of COPD remain to be understood, but an important feature of the disease is the upregulation of inflammatory processes that results in apoptosis of type 1 pneumocytes and possible endothelial cells, as well as proteolysis of the connective tissue, particularly elastin fibers, with destruction of alveolar walls (emphysema). ${ }^{61}$

MSCs are considered a potential therapy in COPD because of their immunomodulatory effects and the ability to regenerate type 1 and 2 cells in the airspace. MSCs derive from mesoderm and show a multilineage potential, ${ }^{62,63}$ as they have the capacity to give rise to blood, skeletal muscle cells, vascular, fat, and urogenital systems, as well as to connective tissues throughout the body. ${ }^{64}$ Because of their unlimited self-renewal capacity, MSCs show that an in vitro high expansion potential, a genetic and phenotypic stability, can be easily isolated from a small aspirate of BM expanded with high efficiency, shipped from the laboratory to the bedside. ${ }^{65}$

MSCs show anti-inflammatory, immunomodulatory, and regenerative capacities. They secrete anti-inflammatory cytokines that modify the microenvironment within the damaged tissues. They also exert immunomodulatory effects by direct cell-to-cell contact. In fact, MSCs inhibit autoimmune T-cell responses and increase the number of regulatory $\mathrm{T}$ cells. MSCs also inhibit the development and differentiation of dendritic cells and can selectively channel autoimmune $\mathrm{T}$ cells to apoptosis. ${ }^{66}$ Moreover, MSCs are able to migrate to sites of tissue injury and have strong immunosuppressive properties that can be exploited for successful autologous as well as heterologous transplantations. ${ }^{67}$

In 2009, an innovative Phase I clinical study on the use of autologous bone marrow mononuclear cells (BMMCs) in patients with pulmonary emphysema demonstrated that the administration of autologous cells with a pool of BMMCs in patients with advanced-stage COPD is a safe procedure without significant adverse effects. ${ }^{60}$ Furthermore, the reports from patients showed that in the period after the infusion of BMMCs until 20 months later, there was pulmonary function improvement and slowing down of the progressive degenerative condition in terms of maintenance or even increase in the forced expiratory volume in 1 second and forced vital capacity, and increase in forced expiratory volume in 1 second/forced vital capacity. BMMCs had an improvement in their clinical condition, a greater time tolerance without $\mathrm{O}_{2}$ intake, a greater capacity on exertion evaluated as walking distance, without significant fall in $\mathrm{O}_{2}$ saturation, and meaningful improvement in the quality of life, as well as a clinical stable condition. A follow-up of up to 3 years showed an improvement in laboratory parameters (spirometry) and a slowing down in the process of pathological degeneration. ${ }^{60}$ In addition, patients reported improvements in the clinical condition and quality of life. These results suggest a change in the natural process of the disease, even with the small number of patients tested.

In a study performed by Weiss et al, 62 patients with COPD were enrolled. ${ }^{68}$ They were randomized to four intravenous monthly infusions of either allergenic MSCs or vehicle control and were followed for 2 years. Results showed that MSC infusions were well tolerated with no serious or clinically significant adverse effects. In addition, a statistically significant decrease in circulating $\mathrm{C}$-reactive protein at 1 month after the first infusion and for the entire duration of the study was reported in patients receiving MSCs, although there were no significant differences in lung function tests or quality-of-life indicators.

Most of the studies are focused on the potential benefits resulting from the use of MSCs derived from organs other than lung. This is because MSCs derived from the lung (L-MSCs) have only recently been described in mice, ${ }^{69-71}$ humans, ${ }^{50,72}$ and sheep. ${ }^{73,74}$

Two recent studies in an ovine model of emphysema demonstrated significant improvements in tissue mass, perfusion, and diffusion capacity, using L-MSCs delivered intrabronchially on a biological scaffold. These studies 
Table I The most important studies regarding the use of stem cells in chronic obstructive pulmonary disease

\begin{tabular}{|c|c|c|}
\hline Clinical trial & Authors & Year \\
\hline $\begin{array}{l}\text { Lung regeneration and translational implications } \\
\text { of the post-pneumonectomy model }\end{array}$ & Thane K, Ingenito EP, Hoffman AM'16 & 2014 \\
\hline Engineered whole organs and complex tissues & $\begin{array}{l}\text { Badylak SF, Weiss DJ, Caplan A, } \\
\text { Macchiarini } P^{27}\end{array}$ & 2012 \\
\hline $\begin{array}{l}\text { Repopulation of a human alveolar matrix by adult rat type } 2 \\
\text { pneumocytes in vitro; a novel system for type } 2 \text { pneumocyte culture }\end{array}$ & Lwebuga-Mukasa JS, Ingbar DH, Madri JA ${ }^{30}$ & 1986 \\
\hline $\begin{array}{l}\text { Autologous transplantation of adipose tissue-derived stromal } \\
\text { cells ameliorates pulmonary emphysema }\end{array}$ & $\begin{array}{l}\text { Shigemura N, Okumura M, Mizuno S, } \\
\text { Imanishi Y, Nakamura T, Sawa } Y^{42}\end{array}$ & 2006 \\
\hline $\begin{array}{l}\text { Adipose stem cell treatment in mice attenuates lung } \\
\text { and systemic injury induced by cigarette smoking }\end{array}$ & $\begin{array}{l}\text { Schweitzer KS, Johnstone } \mathrm{BH} \text {, } \\
\text { Garrison J, et al }{ }^{48}\end{array}$ & 2011 \\
\hline $\begin{array}{l}\text { Unicentric study of cell therapy in chronic obstructive } \\
\text { pulmonary disease/pulmonary emphysema }\end{array}$ & $\begin{array}{l}\text { Ribeiro-Paes JT, Bilaqui } A \text {, } \\
\text { Greco OT, et al }{ }^{59}\end{array}$ & 2011 \\
\hline $\begin{array}{l}\text { A placebo-controlled, randomized trial of mesenchymal } \\
\text { stem cells in chronic obstructive pulmonary disease }\end{array}$ & $\begin{array}{l}\text { Weiss DJ, Casaburi R, Flannery R, } \\
\text { LeRoux-Williams M, Tashkin DP }{ }^{68}\end{array}$ & 2013 \\
\hline
\end{tabular}

showed that L-MSCs, similar to MSCs, deliver paracrine signals important to alveolar homeostasis and injury repair, although their effectiveness in comparison to BM-MSCs is unknown. . $^{7,75}$

In a recent study by Paxson et al, ${ }^{76}$ performed on murine lung cell dynamics, during lung regeneration, it has been demonstrated that one of the most important factors influencing the regenerative cell capacities is age. In fact, isolated L-MSCs from older mice were characterized by fewer colony-forming units, less growth potential, and telomerase activity, indicating an age-related differentiation potential decrease.

A new and interesting field of investigation is "regenerative photobiostimulation," or having the ability to enhance lung regenerative properties by means of low-level laser irradiation. ${ }^{77}$ Low-level laser therapy contemplates the application of electromagnetic radiations, and its beneficial properties include anti-inflammatory activity, growth factor production, stimulation of angiogenesis, and direct stem cell effects. These effects are mediated through a process that is still not clearly defined and does not involve thermal energy. ${ }^{77}$

In most cases, irrespective of the treated condition or the modality of administration, therapy with stem cells appears relatively safe. However, some risk factors have been reported, both in clinical experience and in animal studies, including tumor formation, unwanted immune responses, and the transmission of microbiological agents. $^{78}$

\section{Conclusion}

At this time, COPD treatment is based on the administration of drugs that are able to reduce symptoms and prevent exacerbations. However, these therapies do not allow for changing the natural history of the disease. Animal and human studies have demonstrated that tissue-specific stem cells and BM-derived cells contribute to lung tissue regeneration and protection, and thus administration of exogenous stem/progenitor cells or the humoral factors responsible for the activation of endogenous stem/progenitor cells may be a potent next-generation therapy for COPD (Table 1). The use of BM-derived stem cells could allow us to repair and regenerate the damaged tissue present in COPD by means of their engraftment into the lung. Another approach could be the in vitro stimulation of stem cells that can be subsequently introduced into the body by means of the photobiostimulation approach. ${ }^{77}$ Thus, a regenerative approach may modulate both local and systemic inflammation and, at the same time, accelerate alveolar epithelial and endothelial turnover, modifying the natural course of COPD. ${ }^{79}$ Moreover, one of the latest findings in cell therapy is represented by the application of the "magnetic targeting" approach for improving cell and tissue engraftment into the damaged organ. It consists in the use of a magnetic cylinder made by superparamagnetic iron oxide nanoparticles surrounding the graft to increase the number of stem cells seeded into the organ. This technique is still in progress, and data show a certain grade of cytotoxicity in airway application. ${ }^{80}$

Finally, the field of regenerative therapies is rapidly progressing, and initial data are very promising. However, the possible indications and potential adverse effects of stem cell therapy have yet to be fully elucidated.

\section{Disclosure}

The authors report no conflicts of interest in this work. 


\section{References}

1. Juckett DA. What determines age-related disease: do we know all the right questions? Age (Dordr). 2010;32(2):155-160.

2. Rennert RC, Sorkin M, Garg RK, Gurtner GC. Stem cell recruitment after injury: lessons for regenerative medicine. Regen Med. 2012;7(6):833-850.

3. Bloom RD, Goldberg LR, Wang AY, Faust TW, Kotloff RM. An overview of solid organ transplantation. Clin Chest Med. 2005;26(4): 529-543, v. v.

4. Siniscalco D, Sullo N, Maione S, Rossi F, D’Agostino B. Stem cell therapy: the great promise in lung disease. Ther Adv Respir Dis. 2008;2(3):173-177.

5. Kotton DN, Morrisey EE. Lung regeneration: mechanisms, applications and emerging stem cell populations. Nat Med. 2014;20(8): 822-832.

6. Global Initiative for Chronic Obstructive Pulmonary Disease. Global Strategy for the Diagnosis, Management, and Prevention of Chronic Obstructive Pulmonary Disease. Global Initiative for Chronic Obstructive Pulmonary Disease; 2014. Avalable from: http://www.goldcopd.org/uploads/users/ files/GOLD_Report_2014_Jun11.pdf. Accessed August 3, 2014.

7. Lopez AD, Shibuya K, Rao C, et al. Chronic obstructive pulmonary disease: current burden and future projections. Eur Respir J. 2006;27(2):397-412

8. World Health Organization. Burden of COPD. Geneva: World Health Organization. Avalable from: http://www.who.int/respiratory/copd/ burden/en/. Accessed August 3, 2014.

9. Cazzola M, Page CP, Calzetta L, Matera MG. Emerging anti-inflammatory strategies for COPD. Eur Respir J. 2012;40(3):724-741.

10. Shi W, Chen F, Cardoso WV. Mechanisms of lung development: contribution to adult lung disease and relevance to chronic obstructive pulmonary disease. Proc Am Thorac Soc. 2009;6(7):558-563.

11. Cazzola M, Matera MG. Bronchodilators: current and future. Clin Chest Med. 2014;35(1):191-201.

12. Kawasumi A, Sagawa N, Hayashi S, Yokoyama H, Tamura K. Wound healing in mammals and amphibians: toward limb regeneration in mammals. Curr Top Microbiol Immunol. 2013;367:33-49.

13. Voss GJ, Kump DK, Walker JA, Voss SR. Variation in salamander tail regeneration is associated with genetic factors that determine tail morphology. PLoS ONE. 2013;8(7):e67274

14. Li C. Histogenetic aspects of deer antler development. Front Biosci (Elite Ed). 2013;5(2):479-489.

15. Wu Y, Wang K, Karapetyan A, et al. Connective tissue fibroblast properties are position-dependent during mouse digit tip regeneration. PLoS ONE. 2013;8(1):e54764.

16. Thane K, Ingenito EP, Hoffman AM. Lung regeneration and translational implications of the postpneumonectomy model. Transl Res. 2014;163(4):363-376.

17. Cagle PT, Thurlbeck WM. Postpneumonectomy compensatory lung growth. Am Rev Respir Dis. 1988;138(5):1314-1326

18. Chen L, Acciani T, Le Cras T, Lutzko C, Perl AK. Dynamic regulation of platelet-derived growth factor receptor $\alpha$ expression in alveolar fibroblasts during realveolarization. Am J Respir Cell Mol Biol. 2012;47(4):517-527.

19. Deslauriers J, Ugalde P, Miro S, et al. Long-term physiological consequences of pneumonectomy. Semin Thorac Cardiovasc Surg. 2011;23(3):196-202.

20. Rudolph AM, Neuhauser EB, Golinko RJ, Auld PA. Effects of pneumonectomy on pulmonary circulation in adult and young animals. Circ Res. 1961;9(4):856-861.

21. Ysasi AB, Belle JM, Gibney BC, et al. Effect of unilateral diaphragmatic paralysis on postpneumonectomy lung growth. Am J Physiol Lung Cell Mol Physiol. 2013;305(6):L439-L445.

22. Brody JS. Time course of and stimuli to compensatory growth of the lung after pneumonectomy. J Clin Invest. 1975;56(4):897-904.

23. Paxson JA, Parkin CD, Iyer LK, Mazan MR, Ingenito EP, Hoffman AM. Global gene expression patterns in the post-pneumonectomy lung of adult mice. Respir Res. 2009;10(1):92.
24. Nolen-Walston RD, Kim CF, Mazan MR, et al. Cellular kinetics and modeling of bronchioalveolar stem cell response during lung regeneration. Am J Physiol Lung Cell Mol Physiol. 2008;294(6): L1158-L1165.

25. Shannon JM. Induction of alveolar type II cell differentiation in fetal tracheal epithelium by grafted distal lung mesenchyme. Dev Biol. 1994;166(2):600-614.

26. Beers MF, Morrisey EE. The three R's of lung health and disease: repair, remodeling, and regeneration. J Clin Invest. 2011;121(6):2065-2073.

27. Badylak SF, Weiss DJ, Caplan A, Macchiarini P. Engineered whole organs and complex tissues. Lancet. 2012;379(9819):943-952.

28. Wagner DE, Bonvillain RW, Jensen T, et al. Can stem cells be used to generate new lungs? Ex vivo lung bioengineering with decellularized whole lung scaffolds. Respirology. 2013;18(6):895-911.

29. Kuttan R, Spall RD, Duhamel RC, Sipes IG, Meezan E, Brendel K. Preparation and composition of alveolar extracellular matrix and incorporated basement membrane. Lung. 1981;159(6):333-345.

30. Lwebuga-Mukasa JS, Ingbar DH, Madri JA. Repopulation of a human alveolar matrix by adult rat type II pneumocytes in vitro. A novel system for type II pneumocyte culture. Exp Cell Res. 1986;162(2):423-435.

31. Price AP, England KA, Matson AM, Blazar BR, Panoskaltsis-Mortari A. Development of a decellularized lung bioreactor system for bioengineering the lung: the matrix reloaded. Tissue Eng Part A. 2010;16(8):2581-2591.

32. Petersen TH, Calle EA, Zhao L, et al. Tissue-engineered lungs for in vivo implantation. Science. 2010;329(5991):538-541.

33. Cortiella J, Niles J, Cantu A, et al. Influence of acellular natural lung matrix on murine embryonic stem cell differentiation and tissue formation. Tissue Eng Part A. 2010;16(8):2565-2580.

34. Hogan BL, Barkauskas CE, Chapman HA, et al. Repair and regeneration of the respiratory system: complexity, plasticity, and mechanisms of lung stem cell function. Cell Stem Cell. 2014;15(2):123-138.

35. Fuchs E, Segre JA. Stem cells: a new lease on life. Cell. 2000;100(1): 143-155.

36. Rankin S. Mesenchymal stem cells. Thorax. 2012;67(6):565-566.

37. Huertas A, Palange P. Circulating endothelial progenitor cells and chronic pulmonary diseases. Eur Respir J. 2011;37(2):426-431.

38. Kajstura J, Rota M, Hall SR, et al. Evidence for human lung stem cells. N Engl J Med. 2011;364(19):1795-1806.

39. Tzouvelekis A, Ntolios P, Bouros D. Stem cell treatment for chronic lung diseases. Respiration. 2013;85(3):179-192.

40. Kubo H. Concise review: clinical prospects for treating chronic obstructive pulmonary disease with regenerative approaches. Stem Cells Transl Med. 2012;1(8):627-631.

41. Zeng C, Wang X, Hu X, Chen J, Wang L. Autologous endothelial progenitor cells transplantation for the therapy of primary pulmonary hypertension. Med Hypotheses. 2007;68(6):1292-1295.

42. Shigemura N, Okumura M, Mizuno S, Imanishi Y, Nakamura T, Sawa Y. Autologous transplantation of adipose tissue-derived stromal cells ameliorates pulmonary emphysema. Am J Transplant. 2006;6(11): 2592-600.

43. Shigemura N, Okumura M, Mizuno S, et al. Lung tissue engineering technique with adipose stromal cells improves surgical outcome for pulmonary emphysema. Am J Respir Crit Care Med. 2006; 174(11):1199-1205.

44. Katsha AM, Ohkouchi S, Xin H, et al. Paracrine factors of multipotent stromal cells ameliorate lung injury in an elastase-induced emphysema model. Mol Ther. 2011;19(1):196-203.

45. Furuya N, Takenaga M, Ohta Y, et al. Cell therapy with adipose tissuederived stem/stromal cells for elastase-induced pulmonary emphysema in rats. Regen Med. 2012;7(4):503-512.

46. Zhen G, Liu H, Gu N, Zhang H, Xu Y, Zhang Z. Mesenchymal stem cells transplantation protects against rat pulmonary emphysema. Front Biosci. 2008;13:3415-3422.

47. Zhen G, Xue Z, Zhao J, et al. Mesenchymal stem cell transplantation increases expression of vascular endothelial growth factor in papain-induced emphysematous lungs and inhibits apoptosis of lung cells. Cytotherapy. 2010;12(5):605-614. 
48. Schweitzer KS, Johnstone BH, Garrison J, et al. Adipose stem cell treatment in mice attenuates lung and systemic injury induced by cigarette smoking. Am J Respir Crit Care Med. 2011;183(2):215-225.

49. Hind $M$, Maden $M$. Is a regenerative approach viable for the treatment of COPD? Br J Pharmacol. 2011;163(1):106-115.

50. Lama VN, Smith L, Badri L, et al. Evidence for tissue-resident mesenchymal stem cells in human adult lung from studies of transplanted allografts. J Clin Invest. 2007;117(4):989-996.

51. McGowan S, Jackson SK, Jenkins-Moore M, Dai HH, Chambon P, Snyder JM. Mice bearing deletions of retinoic acid receptors demonstrate reduced lung elastin and alveolar numbers. Am J Respir Cell Mol Biol. 2000;23(2):162-167.

52. Massaro GD, Massaro D. Postnatal treatment with retinoic acid increases the number of pulmonary alveoli in rats. Am J Physiol. 1996;270(2 Pt 1):L305-L310.

53. Roth MD, Connett JE, D'Armiento JM, et al; FORTE Study Investigators. Feasibility of retinoids for the treatment of emphysema study. Chest. 2006;130(5):1334-1345.

54. Mao JT, Goldin JG, Dermand J, et al. A pilot study of all-trans-retinoic acid for the treatment of human emphysema. Am J Respir Crit Care Med. 2002;165(5):718-723.

55. Stolk J, Stockley RA, Stoel BC, et al. Randomised controlled trial for emphysema with a selective agonist of the $\gamma$-type retinoic acid receptor. Eur Respir J. 2012;40(2):306-312.

56. Jones PW, Rames AD. TESRA (Treatment of Emphysema with a Selective Retinoid Agonist) Study Results [abstract]. Am J Respir Crit Care Med. 2011;183:A6418.

57. Antunes MA, Laffey JG, Pelosi P, Rocco PR. Mesenchymal stem cell trials for pulmonary diseases. J Cell Biochem. 2014;115(6): 1023-1032.

58. Horiguchi M, Kojima H, Sakai H, Kubo H, Yamashita C. Pulmonary administration of integrin-nanoparticles regenerates collapsed alveoli. J Control Release. 2014 10;187:167-174.

59. Ribeiro-Paes JT, Bilaqui A, Greco OT, et al. Unicentric study of cell therapy in chronic obstructive pulmonary disease/pulmonary emphysema. Int J Chron Obstruct Pulmon Dis. 2011;6:63-71.

60. Kotton DN, Ma BY, Cardoso WV, et al. Bone marrow-derived cells as progenitors of lung alveolar epithelium. Development. 2001;128(24): 5181-5188.

61. Barnes PJ. Immunology of asthma and chronic obstructive pulmonary disease. Nat Rev Immunol. 2008;8(3):183-192.

62. Deans RJ, Moseley AB. Mesenchymal stem cells: biology and potential clinical uses. Exp Hematol. 2000;28(8):875-884.

63. Bianco P, Riminucci M, Gronthos S, Robey PG. Bone marrow stromal stem cells: nature, biology, and potential applications. Stem Cells. 2001;19(3):180-192.

64. Blocki A, Wang Y, Koch M, et al. Not all MSCs can act as pericytes: functional in vitro assays to distinguish pericytes from other mesenchymal stem cells in angiogenesis. Stem Cells Dev. 2013;22(17):2347-2355.
65. D'Agostino B, Sullo N, Siniscalco D, De Angelis A, Rossi F. Mesenchymal stem cell therapy for the treatment of chronic obstructive pulmonary disease. Expert Opin Biol Ther. 2010;10(5):681-687.

66. Inamdar AC, Inamdar AA. Mesenchymal stem cell therapy in lung disorders: pathogenesis of lung diseases and mechanism of action of mesenchymal stem cell. Exp Lung Res. 2013;39(8):315-327.

67. Le Blanc K, Pittenger M. Mesenchymal stem cells: progress toward promise. Cytotherapy. 2005;7(1):36-45.

68. Weiss DJ, Casaburi R, Flannery R, LeRoux-Williams M, Tashkin DP. A placebo-controlled, randomized trial of mesenchymal stem cells in COPD. Chest. 2013;143(6):1590-1598.

69. Summer R, Fitzsimmons K, Dwyer D, Murphy J, Fine A. Isolation of an adult mouse lung mesenchymal progenitor cell population. Am J Respir Cell Mol Biol. 2007;37(2):152-159.

70. McQualter JL, Brouard N, Williams B, et al. Endogenous fibroblastic progenitor cells in the adult mouse lung are highly enriched in the sca-1 positive cell fraction. Stem Cells. 2009;27(3):623-633.

71. Reynolds SD, Shen H, Reynolds PR, et al. Molecular and functional properties of lung SP cells. Am J Physiol Lung Cell Mol Physiol. 2007;292(4):L972-L983.

72. Jarvinen L, Badri L, Wettlaufer S, et al. Lung resident mesenchymal stem cells isolated from human lung allografts inhibit T cell proliferation via a soluble mediator. J Immunol. 2008;181(6):4389-4396.

73. Ingenito EP, Sen E, Tsai LW, Murthy S, Hoffman A. Design and testing of biological scaffolds for delivering reparative cells to target sites in the lung. J Tissue Eng Regen Med. 2010;4(4):259-272.

74. Ingenito EP, Tsai L, Murthy S, Tyagi S, Mazan M, Hoffman A. Autologous lung-derived mesenchymal stem cell transplantation in experimental emphysema. Cell Transplant. 2012;21(1):175-189.

75. Summer R, Fine A. Mesenchymal progenitor cell research: limitations and recommendations. Proc Am Thorac Soc. 2008;5(6):707-710.

76. Paxson JA, Gruntman AM, Davis AM, Parkin CM, Ingenito EP, Hoffman AM. Age dependence of lung mesenchymal stromal cell dynamics following pneumonectomy. Stem Cells Dev. 2013;22(24): 3214-3225.

77. Lin F, Josephs SF, Alexandrescu DT, et al. Lasers, stem cells, and COPD. J Transl Med. 2010;8(1):16.

78. Herberts CA, Kwa MS, Hermsen HP. Risk factors in the development of stem cell therapy. J Transl Med. 2011;9(1):29.

79. Tzouvelekis A, Laurent G, Bouros D. Stem cell therapy in chronic obstructive pulmonary disease. Seeking the Prometheus effect. Curr Drug Targets. 2013;14(2):246-252.

80. Ordidge KL, Gregori M, Kalber TL, Lythgoe MF, Janes SM, Giangreco A. Coupled cellular therapy and magnetic targeting for airway regeneration. Biochem Soc Trans. 2014;42(3):657-661.
International Journal of COPD

\section{Publish your work in this journal}

The International Journal of COPD is an international, peer-reviewed journal of therapeutics and pharmacology focusing on concise rapid reporting of clinical studies and reviews in COPD. Special focus is given to the pathophysiological processes underlying the disease, intervention programs, patient focused education, and self management protocols.
Dovepress

This journal is indexed on PubMed Central, MedLine and CAS. The manuscript management system is completely online and includes a very quick and fair peer-review system, which is all easy to use. Visit http://www.dovepress.com/testimonials.php to read real quotes from published authors. 